\title{
First photosensitized enantiodifferentiating isomerization by optically active sensitizer immobilized in zeolite supercages
}

\author{
Takehiko Wada, ${ }^{a}$ Masayuki Shikimi, ${ }^{a}$ Yoshihisa Inoue, ${ }^{* a b}$ George Lem ${ }^{c}$ and Nicholas J. Turro*c \\ a Department of Molecular Chemistry, Graduate School of Engineering, Osaka University, Yamada-oka, \\ Suita 565-0871, Japan,E-mail: inoue@chem.eng.osaka-u.ac.jp; Fax: +8166879 7923; \\ Tel: +81668797922 \\ ${ }^{b}$ Inoue Photochirogenesis Project, ERATO, JST, 4-6-3 Kamishinden, Toyonaka, 565-0085, Japan \\ c Chemistry Department, Columbia University, 3000 Broadway, New York, NY 10027, USA
}

\begin{abstract}
Received (in Corvallis, OR, USA) 12th June 2001, Accepted 1st August 2001
First published as an Advance Article on the web 4th September 2001
\end{abstract}

Enantiodifferentiating photoisomerization of $(Z)$-cyclooctene sensitized by $(R)$ - or $(S)$-1-methylheptyl benzoate immobilized in zeolite supercages afforded the respective enantiomer pair, (-)- and (+)-(E)-isomer (1E) in 5\% enantiomeric excess, whilst racemic 1E was obtained upon homogeneous-phase photosensitization with the same antipodal sensitizer pair, thus demonstrating for the first time that chirally modified zeolites not only serve as supramolecular photosensitizing media but also enhance the original enantiodifferentiating ability of chiral photosensitizer.

Supramolecular asymmetric photochemistry in chirally modified zeolite media has been a field of considerable current

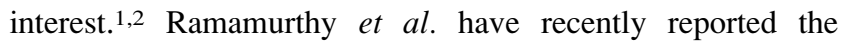
enantioselective and diastereoselective photocyclization with high enantiomeric and diastereomeric excesses. ${ }^{3}$ These asymmetric photoreactions in chirally modified zeolite media reported so far are however not 'catalytic' but 'stoichiometric', requiring at least one equivalent, or even more, chiral inductor per substrate molecule. Hence, the 'catalytic' enantiodifferentiating photosensitization in zeolites modified with chiral sensitizer, if achievable, becomes an attractive versatile method for transferring and multiplying molecular chirality through supramolecular interactions in the excited state. ${ }^{4}$

As a consequence of intensive studies on the enantiodifferentiating photosensitization in homogeneous phase, ever since the first report by Hammond and Cole in 1965,5 the enantiomeric excess (ee) obtained has been improved greatly in recent years. ${ }^{4,6}$ In particular, the enantiodifferentiating geometrical photoisomerization of (Z)-cyclooctene (1Z) sensitized by optically active (poly)alkyl benzene(poly)carboxylates gives $(E)$-isomer (1E) in good ee's (Scheme 1), and the enantioselectivity is dramatically affected by environmental factors, such as temperature, pressure and solvent, accompanying a switching of product chirality in several cases. ${ }^{6}$

In this paper we report a novel supramolecular photochirogenesis system, in which optically active compounds, adsorbed and immobilized in zeolite supercages, sensitize the enantiodifferentiating photoisomerization of an excess amount of substrate dissolved in bulk solution. Such a 'catalytic' enantiodifferentiating photosensitization may be related to

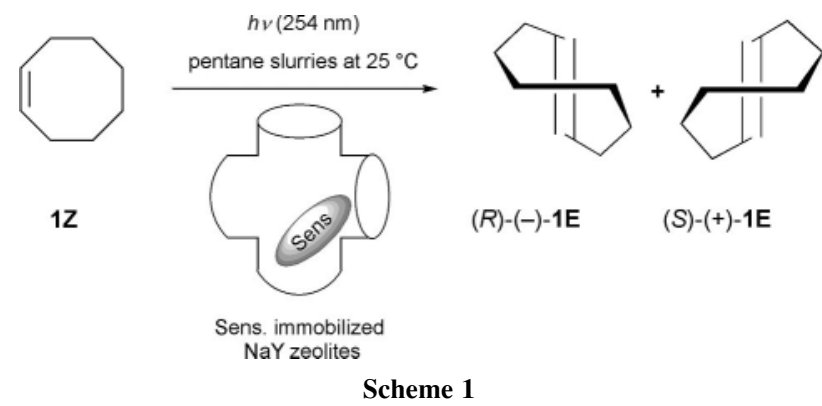

enzymatic reactions, where the substrate molecule diffuses to the binding site of the enzyme and a substrate-enzyme complex is formed prior to the reaction.

The amount of sensitizer added to the zeolite was selected to achieve an average occupancy number of unity $(\langle S\rangle=1){ }^{7}$ The sensitizer-modified zeolites were prepared by stirring the benzene(poly)carboxylate $(63 \mathrm{mmol})$ in pentane $\left(4.0 \mathrm{~cm}^{3}\right)$ with zeolite $\mathrm{NaY}\left(100 \mathrm{mg}\right.$, activated at $\left.450{ }^{\circ} \mathrm{C}\right)$ for $12 \mathrm{~h}$ at $25^{\circ} \mathrm{C}$. The complete adsorption and immobilization of the sensitizer into the zeolite supercages was checked and established by UV, TLC and GC analyses of the bulk solution. ${ }^{8}$ In the cases of methyl benzoate (2a), dimethyl isophthalate (4a) and dimethyl terephthalate (5a), the sensitizer was found to be efficiently immobilized into the zeolite supercages within $6 \mathrm{~h}$, while only $60 \%$ immobilization of dimethyl phthalate (3a) was observed even after $24 \mathrm{~h}$. The adsorbed benzoate and benzenedicarboxylates were completely stable in zeolite supercages and quantitatively recovered by extraction with THF even after 1 week of standing at $25^{\circ} \mathrm{C}$.

For less-bulky chiral sensitizers, such as (-)-1-methylheptyl benzoate $(\mathbf{2 d}, \mathbf{2 e})$, phthalate $(\mathbf{3 d})$, isophthalate $(\mathbf{4 d})$ and terephthalate (5d), the immobilization behavior was similar to that of the corresponding methyl esters. For bulky (-)-menthyl and (-)-bornyl benzoates (2b and 2c), ca. 60-70\% immobilization of sensitizer was observed, while tetramethyl benzenetetracarboxylate showed no appreciable adsorption even after 24 $\mathrm{h}$ at $60{ }^{\circ} \mathrm{C}$. In sharp contrast to the strong adsorption of sensitizers, no adsorption or immobilization of $(Z)$-cyclooctene (1Z) was observed. The highly strained $(E)$-cyclooctene $(\mathbf{1 E})$ produced was shown to be stable in the modified zeolite supercages.

Pentane slurries $(2 \mathrm{~mL})$, containing $\mathbf{1 Z}(315 \mathrm{mmol}$, or 158 mmol $\left.\mathrm{dm}^{-3}\right)$ and NaY $(100 \mathrm{mg})$ modified with sensitizer $(63$ mmol, $\langle S\rangle=1$ ), were irradiated at $254 \mathrm{~nm}$ at $25^{\circ} \mathrm{C}$ under an argon atmosphere to give $\mathbf{1 E}$ as the sole product detected by $\mathrm{GC}$. The sensitizers were stable under the irradiation conditions, as evidenced by the UV spectral and gas chromatographic examinations of THF extracts of the irradiated zeolites. The $E / Z$ ratios and chemical and optical yields, obtained upon photosensitization with modified zeolite media, are listed in Table 1, along with the relevant values for the conventional sensitizations with $\mathbf{2 d}, \mathbf{4 d}$ and $\mathbf{5 d}$ in pentane solution. ${ }^{6 b}$ The $E / Z$ ratios obtained with $\mathbf{2 a}$ and $\mathbf{4 a}$ immobilized in the zeolite supercages are smaller than the corresponding values obtained upon photosensitization in homogeneous solutions. However, it should be noted that these low $E / Z$ ratios obtained with $2 \mathbf{2 a}$ and $4 \mathbf{a}$ are not inherent to the photosensitization within the zeolite supercages, but are simply attributed to the much higher concentration employed $\left(158 \mathrm{mmol} \mathrm{dm}^{-3}\right)$. Indeed, the ratio almost linearly increased with increasing irradiation time indicating that these are the initial values. It is thus concluded that the less-bulky benzenemono- and benzenedicarboxylates immobilized in the zeolite supercages work as effective sensitizers and further that the immobilized sensitizer and freely 
Table 1 Photosensitized isomerization of $(Z)$ - and $(E)$-cyclooctene $(\mathbf{1 Z}, \mathbf{1 E})$ in sensitizer-immobilized zeolite cavities ${ }^{a}$ and in homogenous solutions

\begin{tabular}{|c|c|c|c|c|c|c|c|c|}
\hline Media & Substrate & Sensitizer & $\begin{array}{l}\text { Absolute } \\
\text { configuration }\end{array}$ & $\begin{array}{l}\text { Irradiation } \\
\text { time/min }\end{array}$ & $E / Z$ & $\begin{array}{l}\text { Conversion } \\
(\%)\end{array}$ & $\begin{array}{l}\text { Yield of 1E } \\
(\%)\end{array}$ & $\% \mathrm{ee}^{b}$ \\
\hline \multirow[t]{3}{*}{ Solution } & $1 Z$ & $\mathbf{2 d}{ }^{c}$ & $R$ & 30 & 0.21 & 22.2 & 16.8 & -0.7 \\
\hline & & $4 d^{c}$ & $R$ & 60 & 0.32 & 37.9 & 20.0 & -0.7 \\
\hline & & $5 \mathbf{d}^{c}$ & $R$ & 60 & 0.26 & 46.0 & 14.0 & -2.5 \\
\hline \multirow[t]{13}{*}{ Zeolite } & $1 Z$ & $2 a$ & Achiral & 120 & 0.051 & 9.3 & 4.7 & $d$ \\
\hline & & $2 d$ & $R$ & 120 & 0.021 & $e$ & $e$ & -4.5 \\
\hline & & & & 360 & 0.056 & $e$ & $e$ & -3.8 \\
\hline & $1 E$ & $2 d$ & $R$ & & & & & \\
\hline & & & & 120 & 2.290 & $e$ & $e$ & 0.0 \\
\hline & & & & 360 & 0.710 & $e$ & $e$ & 0.0 \\
\hline & $1 Z$ & $2 \mathrm{e}$ & $S$ & 240 & 0.041 & $e$ & $e$ & 4.1 \\
\hline & & & & 360 & 0.054 & $e$ & $e$ & 4.5 \\
\hline & & $4 a$ & Achiral & & & & & \\
\hline & & & & 60 & 0.022 & 6.4 & 2.1 & $d$ \\
\hline & & & & 240 & 0.082 & 14.2 & 7.4 & $d$ \\
\hline & & $4 d$ & $R$ & 360 & 0.057 & $e$ & $e$ & -2.5 \\
\hline & & $5 d$ & $R$ & 360 & 0.049 & $e$ & $e$ & -3.5 \\
\hline
\end{tabular}

${ }^{a}$ All irradiations were conducted in pentane slurries at $25^{\circ} \mathrm{C}$. Occupancy number of sensitizer per supercage was unity. ${ }^{b}$ Enantiomeric excess of isolated $1 E$ determined by chiral GC (Supelco $\beta$-Dex 225 column); error in $\%$ ee $< \pm 0.5$; the positive and negative ee values refer to the preferential formation of

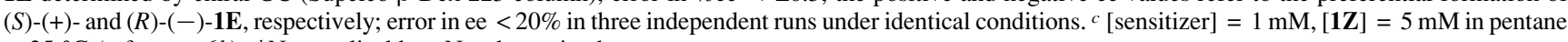
at $25^{\circ} \mathrm{C}$ (reference $\left.6 b\right){ }^{d}$ Not applicable. ${ }^{e}$ Not determined.

diffusing substrate can share the same supercage and interact with each other.

The 1E produced was isolated from the irradiated solution through the silver nitrate extraction technique, ${ }^{6 b}$ and was subjected to chiral GC analysis to yield the ee values shown in Table $1 .{ }^{9}$ A modest ee of $\mathbf{1 E}$, up to $-4.5 \%$ [(-)-1E], was obtained for $(R)-(-)$-1-methylheptyl benzoate $(\mathbf{2 d})$-immobilized $\mathrm{NaY}$ zeolite sensitization. It should be noted that this chiral sensitizer gives nearly racemic 1E $(-0.7 \%$ ee) upon irradiation in homogeneous solutions. The antipodal sensitizer pair $(R)$ - and $(S)$-1-methylheptyl benzoates (2d and $\mathbf{2 e})$ gave the respective enantiomer pair, $(-)$ - and (+)-1E, in -4.5 and $+4.5 \%$ ee, respectively. Significantly, the product ee's obtained with 2d and 2e did not show any appreciable time dependence.

The reverse photoisomerization of $\mathbf{1 E}$ with modified zeolite media was also performed under comparable conditions. Although the photoisomerization from $\mathbf{1 E}$ to $\mathbf{1 Z}$ occurred efficiently in the presence of $\mathbf{2 d}$-modified zeolites, no appreciable ee was observed in the remaining 1E. $(R)-(-)-1-\mathrm{Me}-$ thylheptyl isophthalate (4d) and terephthalate $(\mathbf{5 d})$ immobilized in zeolite as sensitizer also afforded $\mathbf{1 E}$ in -2.5 and $-3.5 \%$ ee, respectively. In contrast to these appreciable ee's of $\mathbf{1 E}$ produced in 4d- or 5d-modified zeolites, much lower, or nearly racemic, $1 \mathbf{E}$ was produced upon sensitization with $4 \mathbf{d}$ or $\mathbf{5 d}$ in pentane solutions at $25^{\circ} \mathrm{C}$.

These results clearly demonstrate for the first time that the confined reaction space provided by the zeolite supercage is a convenient, versatile and reliable tool for enhancing enantiodifferentiating ability of chiral sensitizers and also that such a supramolecular photosensitization system may be regarded as a 'photoenzyme', the functions of which, i.e. complexation and subsequent chemical transformation, are switched on by illuminating the system. Although the observed effects of confinement may not be particularly spectacular in the present cases due to the limited cavity size of NaY zeolite which bars the use of more effective chiral sensitizers such as phthalates, benzene-1,2,4,5-tetracarboxylates and benzenehexacarboxylates, it is important and essential to note that the product ee was steadily enhanced in every case, probably promising a better performance for more size-optimized sensitizer-substratecavity systems.

This unique aspect of immobilization of sensitizer in zeolite supercages might have mainly originated from the decrease in conformational freedom of the adsorbed sensitizer, the restricted direction of approaching $\mathbf{1 Z}$ to the sensitizer, and the different exciplex structure in confined cavities. Thus, temperature effects on the enantiodifferentiating step of asymmetric photoisomerization in modified zeolite media are very inter- esting and important points for future investigation. These effects should be different from those in homogeneous systems, and the entropy effects might be decreased in zeolite media. Temperature effects on ee in supramolecular asymmetric photoreactions in modified zeolite media are now in progress.

The authors at Osaka University are grateful for the generous support of this work by a Grand-in-Aid for Scientific Research from the Ministry of Education, Science, Sports and Culture, Japan, and also by the Asahi Glass Foundation. The authors at Columbia University thank the National Science Foundation (Grant CHE98-12676). This work was supported in part by the National Science Foundation and the Department of Energy under Grant NSF CHE98-10367 to the Environmental Molecular Sciences Institute (EMSI) at Columbia University.

\section{Notes and references}

1 D. W. Breck, Zeolite Molecular Sieves: Structure, Chemistry and Use, Wiley, New York, 1974; A. Dyer, An Introduction to Zeolite Molecular Sieves, Wiley, New York, 1988; H. Van Bekkum, E. M. Flanigen and J. C. Jansen, Introduction to Zeolite Science and Practice, Elsevier, Amsterdam, 1991.

2 M. Leibovitch, G. Plovsson, G. Sundarababu, V. Ramamurthy, J. R. Scheffer and J. Trotter, J. Am. Chem. Soc., 1996, 118, 1219; N. A. Kaprinidis, M. S. Landis and N. J. Turro, Tetrahedron Lett., 1997, 38, 2609; A. Joy, R. J. Robbins, K. Pitchumani and V. Ramamurthy, Tetrahedron Lett., 1997, 8825; M. J. Sabater, S. Garcia, M. Alvaro, H. Garcia and J. C. Scaiano, J. Am. Chem. Soc., 1998, 120, 8521; G. Lem and N. J. Turro, Chem. Commun., 2000, 293.

3 A. Joy, J. R. Scheffer and V. Ramamurthy, Org. Lett., 2000, 2, 119; A. Joy, S. Uppili, M. R. Netherton, J. R. Scheffer and V. Ramamurthy, J. Am. Chem. Soc., 2000, 122, 728 .

4 H. Rau, Chem. Rev., 1983, 83, 535; Y. Inoue, Chem.Rev., 1992, 92, 741; J. P. Pete, Adv. Photochem., 1996, 21, 135; S. R. L. Everitt and Y. Inoue, in Molecular and Supramolecular Photochemistry, ed. V. Ramamurthy and K. S. Schanze, Marcel Dekker, New York, 1999, Vol. 3, p. 71.

5 G. S. Hammond and R. S. Cole, J. Am. Chem. Soc., 1965, 87, 3256.

6 (a) Y. Inoue, T. Yokoyama, N. Yamasaki and A. Tai, J. Am. Chem. Soc., 1989, 111, 6480; (b) Y. Inoue, N. Yamasaki, T. Yokoyama and A. Tai, J. Org. Chem., 1992, 57, 1332; (c) Y. Inoue, H. Ikeda, M. Kaneda, T. Sumimura, S. R. L. Everitt and T. Wada, J. Am. Chem. Soc., 2000, 122, 406.

7 The occupancy number, which is presented as $\langle S\rangle$, is defined as the average number of guest molecules per supercage.

8 The immobilization of sensitizers into zeolite supercages was checked by TLC and GC analyses of the bulk pentane solution and the immobilized amount was qualitatively determined by UV absorption at $280 \mathrm{~nm}$.

9 We had carefully checked the reproducibility of product ee in three independent runs under identical conditions to obtain an error well below $20 \%$ of the obtained \%ee value in each case. 